\title{
Modification of a Wastewater Decontamination Station: Chemical, Ecotoxicological, and Technical-Economic Impacts
}

Elise EUVRARD ${ }^{1}$, Nadia MORIN-CRINI ${ }^{1 *}$, Julien CORNU², Xavier HUTINET², Sophie GAVOILLE³ ${ }^{3}$ Céline LAGARRIGUE ${ }^{4}$, Peter WINTERTON ${ }^{5}$ and Grégorio CRINI ${ }^{1}$

${ }^{1}$ Université de Franche-Comté, Chrono-environnement, UMR 6249 UFC/CNRS usc INRA, 16, Route de Gray 25030 Besançon cedex, France

${ }^{2}$ SILAC Industrie, Champlitte, 70000, France

${ }^{3}$ Agence de l'Eau Rhône-Méditerranée-Corse, Délégation de Besançon, 34 rue de la Corvée, Besançon, 25000, France

${ }^{4}$ Agence de l'Eau Rhône-Méditerranée-Corse, Département des Interventions et des Actions de Bassin, 2-4 Allée de Lodz, 69363, Lyon cedex 07, France

${ }^{5}$ Université de Paul Sabatier, UFR Langues, 118 Route de Narbonne, 31062 Toulouse cedex 9, France

\begin{abstract}
In Europe, industry, and especially the surface treatment and finishing sector considered as one of the major polluters, must continue to reduce pollution outflow from their plants in accordance with the water framework directive (WFD 2000/60/EC). In this paper, we proposed to modify a wastewater treatment plant (WWTP) of a company powder coating on aluminium with the aim to reduce the pollutant flux. The different reactions used for the treatment of the metals and anions were studied: First, we conducted laboratory tests, which, once approved by the company, were then transposed to the industrial scale. We describe the results in terms of chemical abatement after modification. In addition, to compare and to evaluate the toxicity of the effluents before and after modification, two ecotoxicological tests were performed. Overall, a technical-economic study confirmed the utility of the chemical modifications carried out.
\end{abstract}

Keywords: Wastewater treatment plant; Industrial discharge water; Chemical abatement; Daphnia test; Germination rate; Financial analysis

\section{Introduction}

In Europe, legislation concerning water policy has become increasingly strict since 1976 with the introduction of several important guidelines, including the Water Framework Directive 2000 [1] (WFD). The WFD established a community framework for water policy in the European Union and has set ambitious goals: to reach a good chemical and ecological state for all the water bodies by a 2015 deadline [2,3]. Since the late 70s, the industry including the surface treatment (ST) sector widely present in Europe and France, has made many efforts to limit its impact on aquatic environments. Investments have been made to improve wastewater treatment technologies and reduce mineral and organic pollution. The treatment choices made by the ST sector have focused essentially on physico-chemical treatment methods relying on the insolubilisation of pollutants present in the wastewaters [4-7]. These actions showed good results, but focused on the best known pollutions like suspended matter, oxidizable materials and precipitated substances. Nowadays, the regulations require taking into account not only new pollutants (as part of the WFD, the list of these substances continues to lengthen), but also to keep on efforts to decrease the flow of pollution released into the environment. On this last point, the question that arises is: how to improve the operation of waste-water treatment plants (WWTP)? Several types of complementary actions to strengthen standard decontamination practices can be considered, placed upstream (preventive actions) or downstream of the wastewater treatment plant (curative actions). The choice then depends on the goals such as, for example, the reduction of water withdrawals, recycling treated water, reduced pollution flow or zero discharge pollution. Technical constraints should also be taken into account and especially economic factors. In general, three ways are possible: i) depollution at source (recycling and treatment of specific effluents by ion exchange resins, oil removal, etc.), ii) the addition of so-called finishing processes (activated carbon, membrane filtration, evaporation, etc.), iii) optimizing the existing WWTP. It is well known that a finishing treatment can be considered only when residual pollution concentrations are low, in order to avoid for example, rapid saturation of carbon filters or membrane clogging which can result in significant financial costs. But our team has recently shown that, although it may comply with the regulations, ST effluent treated by physical-chemical processes still contains a significant but variable pollutant load. Indeed, existing WWTP are not used in their optimal conditions $[8,9]$. This observation has also been noted in other types of industrial effluents by several researchers [6,7]. Before investing in relatively expensive finishing treatment (membrane filtration, evaporation, etc.), it is necessary to optimize the WWTP.

In this context, we modified the operating diagram of the WWTP of a powder coating factory specialized in aluminium, in order to reduce the flow of pollutants. The experimental procedure was as follows: first, we conducted laboratory tests, which, once approved by the company, were then transposed to the industrial scale. Then, we optimized the different steps of the WWTP by changing various parameters including $\mathrm{pH}$, reagents, stirring and contact time. To evaluate the environmental benefits of the chemical modification of the WWTP, standardized ecological tests were performed on a seed germination and mobility of a freshwater crustacean. This study describes i) the results obtained in terms of chemical abatement after the introduction on the industrial site of the modifications proposed, ii) biological results in terms of toxicity, and iii) technical and economic analysis brought about by the modifications in the WWTP.

\section{Materials and Methods}

\section{WWTP}

This study was conducted in partnership with the ST Company Silac located at Champlitte (Haute-Saône, France). Silac is specialized in aluminium treatment with powder coating finishing intended mainly

*Corresponding author: Nadia Morin-Crini, University de Franche-Comté, Chrono-environnement, UMR 6249 UFC/CNRS usc INRA, 16, Route de Gray 25030 Besancon cedex, France, Tel: +33 3816657 86; Fax: +33 381666083 E-mail: nadia.crini@univ-fcomte.fr

Received December 12, 2014; Accepted January 20, 2015; Published February 25, 2015

Citation: EUVRARD E, MORIN-CRINI N, CORNU J, HUTINET J, GAVOILLE S et al. (2015) Modification of a Wastewater Decontamination Station: Chemical, Ecotoxicological, and Technical-Economic Impacts. J Environ Anal Chem 2: 129 doi:10.41722380-2391.1000129

Copyright: (c) 2015 EUVRARD E, et al. This is an open-access article distributed under the terms of the Creative Commons Attribution License, which permits unrestricted use, distribution, and reproduction in any medium, provided the original author and source are credited. 
for the construction sector. The company uses large volumes of water and generates an average of $60 \mathrm{~m}^{3}$ per day of discharge water (DW). The aluminium processing performed requires several treatment steps that consume large quantities of water such as alkaline degreasing, acid pickling, conversion and rinses. During these steps, several chemicals are released as two major types of waste, alkaline effluent (rinse and concentrated alkali), and acidic effluents (rinses, concentrated acid and chromic baths, and rinses). These effluents, which mainly contain aluminium, fluoride and hexavalent chromium, are the major environmental concern for the company. These effluents are sent to the WWTP for chemical insolubilisation (Figure 1, WWTP before optimization). The steps involved are: 1) separation and storage of
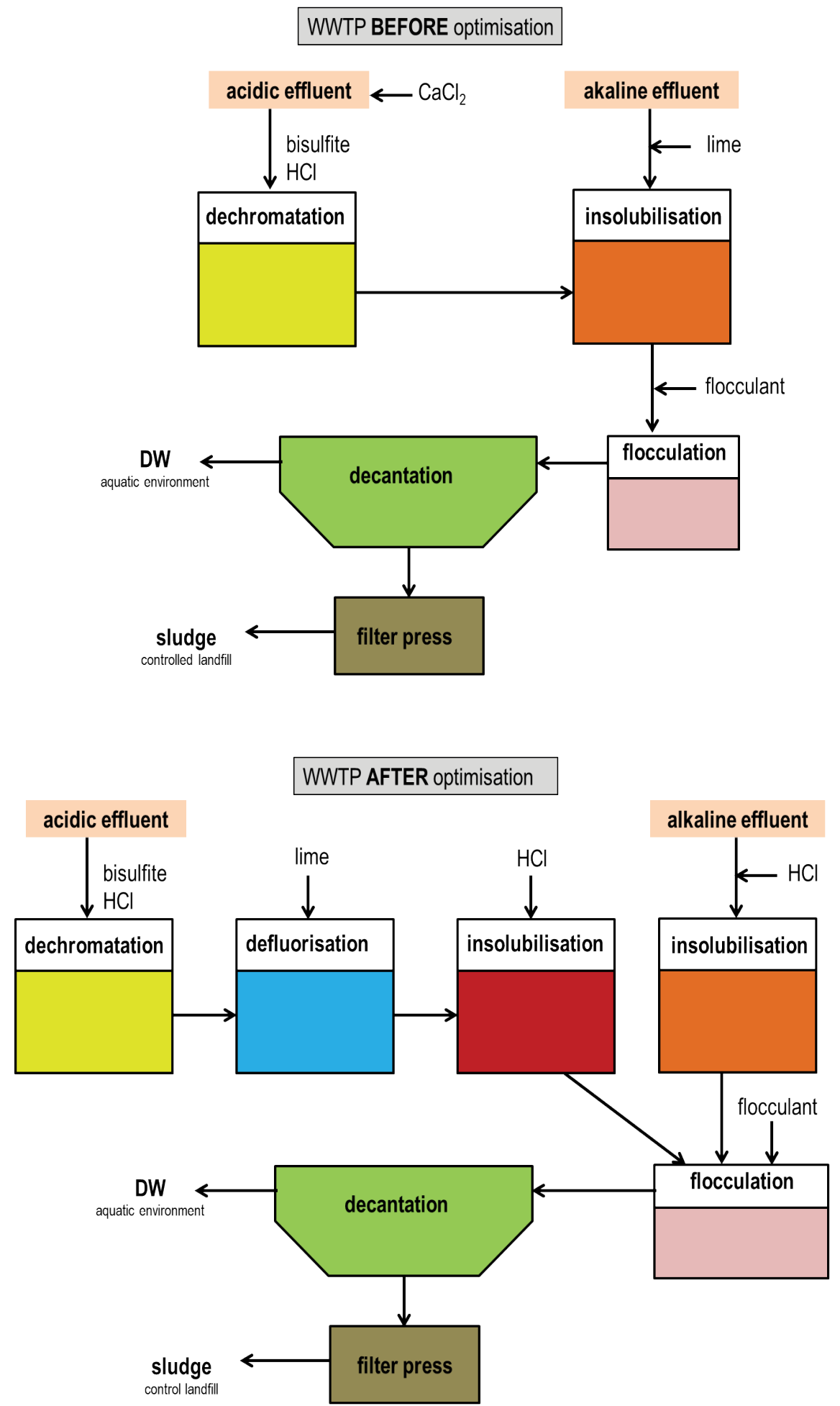

Figure 1: Physico-chemical treatment plant used by Silac industry for the removal of pollutants from effluent, before and after modification. 
effluents, 2) dechromatation of acid effluents, 3) insolubilisation of the global effluent, 4) flocculation with an anionic polymer, 5) decantation, 6) sludge treatment by a filter press, the resulting cake being sent to a controlled landfill and 7) release of treated effluent into the aquatic environment, if it complies with the regulatory standards (Table 1, [5]).

\section{Water parameters measured}

Several water parameters were measured such as $\mathrm{pH}$ (WTW, pH 315i, Alès, France), conductivity (WTW 197i Profiline COND, Alès, France) and chemical oxygen demand (COD Macherey-Nagel, Nanocolor VIS Hoerdt, France) using standard protocols. Chemicals (aluminium, fluoride, etc.) were measured by photometry (MachereyNagel, Nanocolor VIS Hoerdt, France). The method involves using standard test kits and measuring each parameter directly in microtubes with preprogrammed methods. All protocols have been previously described in detail [10].

\section{Method used}

Allowing the simulation of industrial process in the laboratory, the optimization $(\mathrm{pH}$, amount of reagents, stirring, contact time) of the chemical reactions involved (dechromatation, insolubilisation, flocculation) was carried out using a conventional jar-test (Fisher, Illkirch, France) which is a pilot-scale test simulating the coagulation/ insolubilisation/flocculation process. The jar-test process can be summarized as follows: For each sample a number of beakers (jars) are filled with equal amounts of the water and each beaker is then treated with, for example, a different dose of the chemical; by comparing the final water quality achieved in each beaker, the effect of the different treatment parameters can be determined. For treatment of chromium wastes, hexavalent chromium must be reduced to the trivalent state with sodium bisulfite, and then precipitated with lime. This is referred to as a reduction/precipitation process which was optimized accordingly Sancey and Crini [9]. In the lime insolubilisation process [7], anions such as $\mathrm{F}$ and metals such as $\mathrm{Al}$ precipitated in the forms of calcium fluoride precipitates and metal hydroxides respectively. Insolubilisation is accompanied by flocculation because the fine precipitate particles in suspension need to be aggregated to improve solid/liquid separation in the clarifier [7].

\begin{tabular}{|c|c|c|c|c|}
\hline $\begin{array}{c}\text { Parameters or } \\
\text { Substances }\end{array}$ & $\begin{array}{c}\text { Discharge } \\
\text { Concentration } \\
\text { Allowed } \\
\text { (mg/l) }\end{array}$ & $\begin{array}{c}\text { Total Daily } \\
\text { Outflow } \\
\text { Allowed } \\
\mathbf{( k g / d )}\end{array}$ & $\begin{array}{c}\text { Analysis } \\
\text { Frequency }\end{array}$ & $\begin{array}{c}\text { Actual Daily } \\
\text { Outflow (kg/d) }\end{array}$ \\
\hline $\mathrm{pH}$ & $6.5-9$ & - & continuous & \\
\hline $\mathrm{SS}$ & 25 & 2.5 & daily & 0.41 \\
\hline $\mathrm{COD}$ & 150 & 15 & daily & 4.42 \\
\hline phosphorus & 3 & 0.3 & weekly & 0.007 \\
\hline $\mathrm{Zn}$ & 3 & 0.3 & weekly & 0.003 \\
\hline $\mathrm{Cu}$ & 2 & 0.2 & weekly & 0.007 \\
\hline $\mathrm{Ni}$ & 2 & 0.2 & weekly & 0.007 \\
\hline $\mathrm{Ti}$ & 2 & 0.2 & weekly & 0.002 \\
\hline $\mathrm{Fe}$ & 5 & 0.5 & weekly & 0.01 \\
\hline $\mathrm{Al}$ & 5 & 0.5 & weekly & 0.09 \\
\hline $\mathrm{Cr}(\mathrm{III})$ & 0.9 & 0.09 & weekly & 0.006 \\
\hline $\mathrm{Cr}(\mathrm{VI})$ & 0.1 & 0.01 & daily & 0.0007 \\
\hline fluoride & 30 & 2.5 & weekly & 2.3 \\
\hline $\mathrm{AOX}$ & 5 & 0.5 & biannual & 0.006 \\
\hline $\mathrm{TP}$ & 4 & 0.4 & biannual & 0.0001 \\
\hline $\mathrm{HI}$ & 0.5 & 0.05 & weekly & 0.02 \\
\hline
\end{tabular}

Table 1: Legal limits of discharge parameters authorized in industrial DW (French law of $5^{\text {th }}$ September 2006, [5] and actual annual release (data for 2012).

\begin{tabular}{|l|c|c|c|c|c|}
\hline $\begin{array}{l}\text { parameters or } \\
\text { substances }\end{array}$ & DW 1 & DW 2 & DW 3 & DW 4 & DW 5 \\
\hline sampling date & January 6th & May 4th & June 29th & September 18th & November 30th \\
\hline $\mathrm{pH}$ & 7.5 & 7.7 & 7.5 & 7.9 & 7.9 \\
\hline $\mathrm{SS}$ & 12 & 9 & 8 & $<2$ & 4 \\
\hline $\mathrm{COD}$ & 95 & 67 & 67 & $<60$ & 105 \\
\hline phosphorus & $<0.2$ & $<0.2$ & $<0.2$ & $<0.2$ & $<0.2$ \\
\hline $\mathrm{Zn}$ & $<0.1$ & $<0.1$ & $<0.1$ & $<0.1$ & $<0.1$ \\
\hline $\mathrm{Cu}$ & $<0.2$ & $<0.2$ & $<0.2$ & $<0.2$ & $<0.2$ \\
\hline $\mathrm{Ni}$ & $<0.2$ & $<0.2$ & $<0.2$ & $<0.2$ & $<0.2$ \\
\hline $\mathrm{Ti}$ & 0.107 & $<0.05$ & $<0.05$ & $<0.05$ & $<0.05$ \\
\hline $\mathrm{Fe}$ & $<0.2$ & 0.486 & 0.549 & $<0.2$ & 0.244 \\
\hline Al & $\mathbf{1 . 7 8}$ & $\mathbf{1 . 8}$ & $\mathbf{1 . 8 7}$ & $\mathbf{0 . 6 5 2}$ & $\mathbf{0 . 5 2 3}$ \\
\hline $\mathrm{Cr}$ (III) & 0.145 & 0.247 & 0.124 & 0.050 & 0.011 \\
\hline $\mathrm{Cr}(\mathrm{VI})$ & $<0.02$ & $<0.02$ & $<0.02$ & $<0.02$ & $<0.02$ \\
\hline fluoride & $\mathbf{3 0}$ & $\mathbf{3 7}$ & $\mathbf{3 9}$ & $\mathbf{3 3}$ & $\mathbf{2 6}$ \\
\hline $\mathrm{AOX}$ & $<0.06$ & 0.09 & $<0.06$ & 1.05 & $<0.06$ \\
\hline $\mathrm{TP}$ & $<0.00002$ & 0.00005 & $<0.00002$ & 0.00002 & $<0.00002$ \\
\hline $\mathrm{HI}$ & $<0.5$ & $<0.5$ & $<0.5$ & $<0.5$ & $<0.5$ \\
\hline
\end{tabular}

Table 2: Physico-chemical characteristics of the five discharge waters from the WWTP before modification (parameters and concentrations expressed in $\mathrm{mg} / \mathrm{l}$; data from 2012.

\section{Bioassays}

Two types of standardized bioassays were conducted on industrial DW. The first bioassay tested the immobilization of the species Daphnia magna (Arthropoda, Daphniidae) according to the standard NF EN ISO 6341. These bioassays, subcontracted to an external accredited laboratory, allowed the determination of the effective concentration which inhibited mobility of an individual by $50 \%$ during an exposure time of 24 hours, noted $\mathrm{EC}_{50}-24 \mathrm{~h}$. Five daphnia were exposed to $10 \mathrm{ml}$ of the test solution; four replicates are made for each solution tested. The second bioassay measured germination of lettuce Lactuca sativa, (Spermaphyta, Asteraceae) seed. These tests, realized in our laboratory, are described in the standard AFNOR $\mathrm{N}^{\circ}$ NF X 31-201. The method involves placing $4 \mathrm{~mL}$ of demineralized water (control) or $\mathrm{DW}$, in a Petri dish containing two filter paper discs (ashless). Thirty lettuce seeds were then placed in each box in the dark at constant temperature $\left(20^{\circ} \mathrm{C}\right)$ for seven days. Three replicates were carried out per solution tested. After the test, germination rate was calculated using the ratio between the number of germinated seeds in the sample and the number of germinated seeds in the control. As recommended by the French standard method, germination rate under $90 \%$ is unacceptable for control conditions. These ecotoxicological data were processed using $\mathrm{R}$ software (version 3.0.2, R Development Core Team). A Kruskal-Wallis test was used to compare the germination rates before and after the modification of the WWTP. The level of significance was taken to be 0.05

\section{Results and Discussion}

\section{Industrial problematic}

To perform physical-chemical monitoring in order to understand the operation of the WWTP and to follow the concentration variability of the pollutants in the DW, analytical monitoring was performed over the year 2012 with one analysis per week on a DW sample characteristic of a whole day's activity. Table 2 shows, the concentrations of several substances and parameters such as suspended solids (SS), chemical oxygen demand (COD), adsorbable organic halides (AOX), tributylphosphate (TP) and hydrocarbon index (HI) for five DW samples. These results showed high concentrations of 
fluoride and aluminium, while other substances $(\mathrm{Cu}, \mathrm{Fe}, \mathrm{Cr}$ (III), etc.) and parameters (SS, COD, etc.) were far below regulatory values. The two major industrial problems concerned aluminium (outflow in 2012, $0.09 \mathrm{~kg}$ for $0.5 \mathrm{~kg}$ per day authorized, (Table 1) and fluoride (outflow in $2012,2.3 \mathrm{~kg}$ for $2.5 \mathrm{~kg}$ per day authorized, (Table 1). However, for toxicity reasons, the company also pay attention to the concentration of total chromium (outflow in 2012, $0.0067 \mathrm{~kg}$ for $0.1 \mathrm{~kg}$ per day authorized) and hexavalent chromium (even though in the five DW analyzed the value is below the quantification limit (Table 2)), and the water parameter COD (outflow in 2012, $4.42 \mathrm{~kg}$ for $15 \mathrm{~kg}$ per day authorized, Table 1). For aluminium and fluoride, the concentrations in DW were variable (Table 2): this is accounted for by the volume of metal parts treated which was also variable. Indeed, during periods on intense industrial activity DW were more concentrated particularly in aluminium. This first monitoring showed that DW complied with current regulations, except for fluoride which is extremely difficult to reduce to below the threshold of $30 \mathrm{mg} / \mathrm{l}$.

\section{Implementation of the WWTP modification}

To reduce the pollutant outflow in DW, especially fluoride, we proposed to change the way the WWTP operates as described in Figure 1 (WWTP after optimization) by treating the two types of effluent individually. The idea was to insolubilize aluminium and fluoride separately, in particular to take account of the metal precipitation range [11]. Indeed aluminium, like chromium, provides highly soluble amphoteric hydroxides in alkaline medium $(\mathrm{pH}>8.5)$ and which can be dissolved again in some other $\mathrm{pH}$ range which could for example be selected for the precipitation of other pollutants. However, the insolubility of anions like fluoride is most effective at very high $\mathrm{pH}$ $(\mathrm{pH}>10.5)$. Initially, in the case of Silac industry, the aluminium element was chosen as the focus, partly because of the industrial activity, during the precipitation step ( $\mathrm{pH}$ of insolubilisation step: 7.5) to the detriment of fluoride ions which precipitate at higher $\mathrm{pH}$ (close to 10). To help fluoride precipitation, the WWTP used calcium chloride precipitant that was introduced in the acid effluent tank. Preliminary studies (not described in this article) highlighted the chemical benefit, in terms of abatement, of the separation in the insolubilisation step of alkaline and acid effluents to allow the utilization of two different $\mathrm{pH}$ ranges for precipitation. Another result supported the separation of the treatments. Indeed, analytical monitoring over several months showed that the composition of the two effluents was certainly variable quantitatively but from qualitative point of view the overall results were quite constant. Aluminium was mainly in alkali effluent and fluoride in the acidic effluent, with non-negligible concentrations of hexavalent chromium and aluminium. Moreover, in the case of acid effluents at the outlet of the dechromatation step we proposed to establish a more selective double precipitation for pollutant removal, precipitation with lime for fluoride followed by precipitation with hydrochloric acid for residual aluminium. The results (amphoteric hydroxides, precipitation $\mathrm{pH}$ and effluent composition) led us to propose a new general diagram for the wastewater treatment. Once validated by the industrial, laboratory tests were then replicated full scale (new WWTP described in Figure 1 after optimization).

\section{Optimization of the different phases of treatments in the WWTP scheme proposed}

Following the modification on-site, insolubilisation was then optimized, like that of fluoride (just after the dechromatation step). This precipitation step consists in varying the $\mathrm{pH}$, by adding sodium hydroxide or hydrochloric acid, in order to achieve the optimum range of precipitation for particular metal hydroxides. However, as the optimum $\mathrm{pH}$ depends on the mineral (metal), it is usually fixed to optimise the precipitation of the target metal in the effluent. The choice is often difficult, because it is also necessary to take into account all the pollutants in the DW. Figure 2 shows that, in the case of the acid effluent precipitation by lime, the more the $\mathrm{pH}$ increases the more fluoride precipitates. The optimal $\mathrm{pH}$ is about 12 . However, at this $\mathrm{pH}$, the amount of lime to be used is twofold that for a $\mathrm{pH}$ less than 11.5 , which not only produces a larger volume of sludge, but also additional cost (reagents, sludge treatment) significant for the company. So, we chose to precipitate fluoride at $\mathrm{pH} 11$. Moreover, this selective precipitation of fluoride allowed us to dispense with the use of calcium chloride in the original WWTP (Figure 1, before optimization). In addition, optimization of flocculation, by acting on the preparation and maturation of the flocculant before use, on the method of injection into the tank, on the stirring process, on the dose of flocculant injected and on the $\mathrm{pH}$, has enhanced the removal of aluminium and total chromium.

Figure 3 shows the analytical results for total chromium, aluminium and fluoride before and after modification of the WWTP over the two years of monitoring (98 samples). For this comparison,

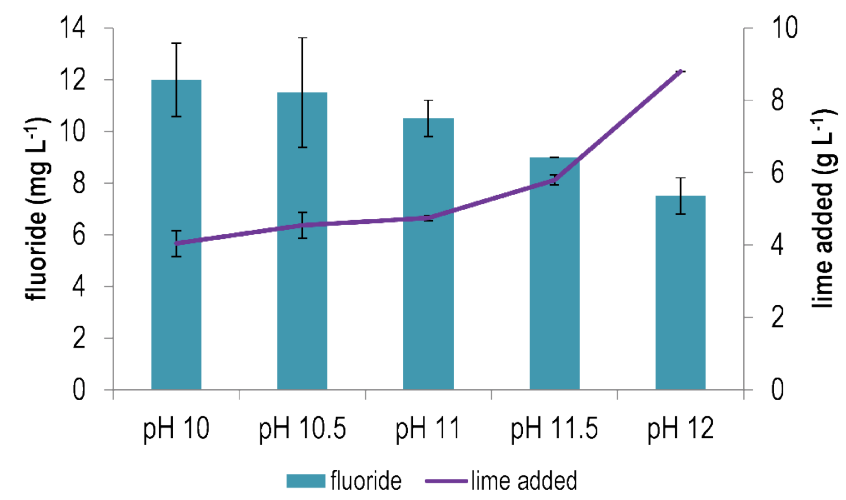

Figure 2: Effects of $\mathrm{pH}$ and lime on fluoride concentration expressed in $\mathrm{mg} / \mathrm{l}$ (initial acid effluent: $\mathrm{pH}=3.1$ at $20^{\circ} \mathrm{C}$ and [fluoride] $=375 \mathrm{mg} / \mathrm{l}$ ).

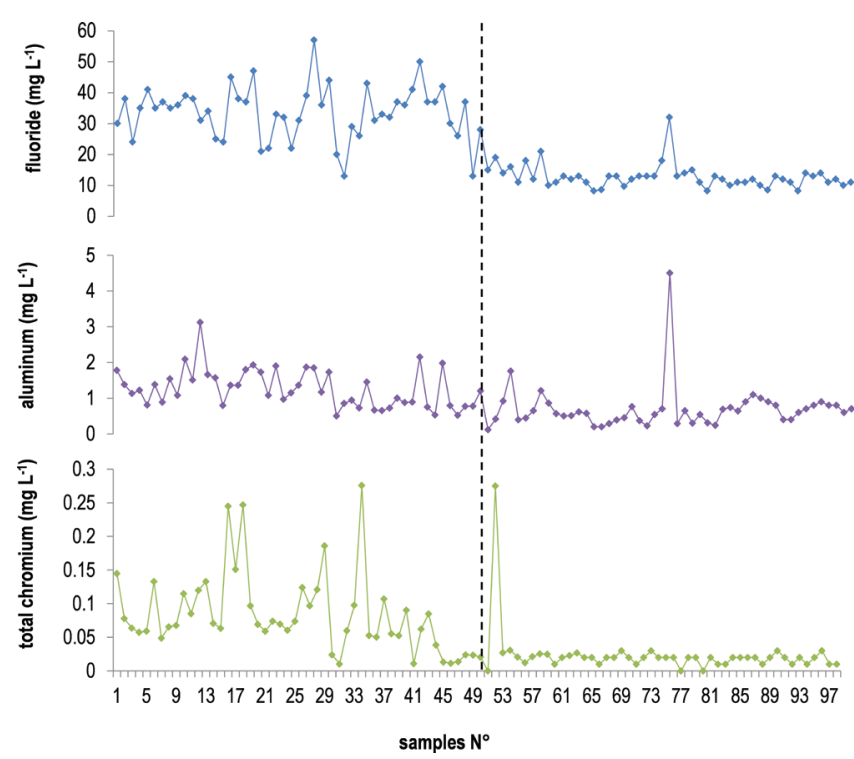

Figure 3: Fluoride, aluminium and total chromium concentration, before and after modification of the WWTP : (- - -: modification). 
Citation: EUVRARD E, MORIN-CRINI N, CORNU J, HUTINET J, GAVOILLE S, et al. (2015) Modification of a Wastewater Decontamination Station: Chemical, Ecotoxicological, and Technical-Economic Impacts. J Environ Anal Chem 2: 129. doi:10.41722380-2391.1000129

\begin{tabular}{|c|c|c|c|c|}
\hline \multirow{2}{*}{$\begin{array}{l}\text { parameters or } \\
\text { substances }\end{array}$} & \multicolumn{2}{|c|}{$\begin{array}{c}\text { average annual } \\
\text { concentrations (mg/l) }\end{array}$} & \multicolumn{2}{|c|}{ average annual flow $(\mathrm{kg} / \mathrm{y})$} \\
\hline & $\begin{array}{c}\text { before } \\
\text { modification }\end{array}$ & $\begin{array}{c}\text { after } \\
\text { modification }\end{array}$ & $\begin{array}{c}\text { before } \\
\text { modification }\end{array}$ & $\begin{array}{c}\text { after } \\
\text { modification }\end{array}$ \\
\hline $\mathrm{pH}\left(20^{\circ} \mathrm{C}\right)$ & 7.8 & 7.6 & - & - \\
\hline SS & 6 & 6.3 & 103.5 & 91.35 \\
\hline COD & 64 & 94 & 1104 & 1363 \\
\hline nitrites & 1.24 & 3.99 & 21.39 & 57.85 \\
\hline phosphorus & 0.1 & 0.07 & 1.725 & 1.015 \\
\hline $\mathrm{Zn}$ & 0.05 & 0.04 & 0.862 & 0.435 \\
\hline $\mathrm{Cu}$ & 0.1 & 0.04 & 1.725 & 0.58 \\
\hline $\mathrm{Ni}$ & 0.1 & 0.03 & 1.725 & 0.435 \\
\hline $\mathrm{Ti}$ & 0.03 & 0.02 & 0.517 & 0.29 \\
\hline $\mathrm{Fe}$ & 0.2 & 0.06 & 3.45 & 0.87 \\
\hline Al & 1.24 & 0.72 & 21.39 & 10.44 \\
\hline Cr (III) & 0.086 & 0.032 & 1.483 & 0.464 \\
\hline $\operatorname{Cr}(\mathrm{VI})$ & 0.01 & 0.003 & 0.172 & 0.043 \\
\hline fluoride & 34 & 14 & 586.5 & 203 \\
\hline AOX & 0.09 & 0.06 & 1.552 & 0.87 \\
\hline TP & 0.002 & 0.00005 & 0.0345 & 0.0007 \\
\hline $\mathrm{HI}$ & 0.25 & 0.45 & 4.31 & 6.52 \\
\hline
\end{tabular}

Table 3: Comparison of annual average for parameters and pollutants expressed in concentration (in $\mathrm{mg} / \mathrm{l}$ ) and in flux (in $\mathrm{kg} / \mathrm{y}$ ) before and after modification.

industrial activity over these two years was quite similar. The average concentrations over the year decreased from $0.096 \mathrm{mg} / \mathrm{l}$ to $0.035 \mathrm{mg} / \mathrm{l}$ for total chromium (64\% of abatement), $1.24 \mathrm{mg} / \mathrm{l}$ to $0.72 \mathrm{mg} / \mathrm{l}$ for aluminium ( $42 \%$ of abatement) and $34 \mathrm{mg} / \mathrm{l}$ to $14 \mathrm{mg} / \mathrm{l}$ for fluoride $(59 \%$ of abatement). These results are highly significant especially for fluoride. Except for the week when a problem occurred due to a malfunction in an $\mathrm{HCl}$ injection system (samples $n^{\circ} 74$, Figure 3 ) concentrations were in the same range without the large fluctuations that occurred before modification. Furthermore, the company found no significant increase in the volume of sludge produced. If we express these concentrations in average annual outflow, we also see a significant decrease not only for these three substances but also for other pollutants present in the DW (Table 3), especially zinc, nickel, iron and AOX. The only negative aspect observed was an increase in the average concentration of COD, which increased by $64 \mathrm{mg} / \mathrm{l}$ to $94 \mathrm{mg} / \mathrm{l}$ before and after optimization. It is difficult at this time to provide an explanation (probably $\mathrm{NaHSO}_{3}$ used as a reducing agent can increase the COD, interfering with the measurement of organic compounds, explaining our unexpected results if used in excess, as suggested by Trunfio and Crini: [12]). Nevertheless, the COD value remained below the prescribed limit of $150 \mathrm{mg} / \mathrm{l}$ (Table 1).

\section{Ecotoxicological impact}

From an environmental point of view, changing the diagram of the WWTP has helped to reduce emissions: $1.148 \mathrm{~kg}$ for total chromium, $10.95 \mathrm{~kg}$ for aluminium and $383.5 \mathrm{~kg}$ for fluoride (mean values) in a year's effluent. To confirm this positive impact on the aquatic environment and to evaluate the toxicity of the outflow, we conducted two bioassays. The first was the Daphnia immobilization test. Whether before or after change, exposure to the DW for $24 \mathrm{~h}$, did not cause immobilization $\left(\mathrm{EC}_{50}>90 \%\right)$. Indeed, no effect was demonstrated, regardless of the DW. To test the toxicity of ST industry DW, other bioassays would be more appropriate. Indeed, the concentrations of the major elements present in the waste, especially aluminium and fluoride, do not seem to be sufficient to have an impact on Daphnia mobility. However, several studies have shown that, on synthetic solutions and at higher concentrations, both can be toxic to the freshwater crustaceans [13-15]. For example, for the $\mathrm{Al}^{3+}$ ion
Khangarot and Ray [14] found a $\mathrm{CE}_{50}-24 \mathrm{~h}$ of $85.9 \mathrm{mg} / \mathrm{l}$ and a $\mathrm{CE}_{50}-48 \mathrm{~h}$ of $59.6 \mathrm{mg} / \mathrm{l}$ with Daphnia magna. In the case of fluoride, Camargo [13] reported a $\mathrm{CL}_{50}-24 \mathrm{~h}$ (median lethal concentration) between 205 and $352 \mathrm{mg} / \mathrm{l}$ for Daphnia.

The second standard bioassay used on the DW was the lettuce seed germination test. The results presented in Figure 4 showed the advantage of optimizing the WWTP. The average germination rate before and after modification were respectively $74.4 \% \pm 6.5 \%$ and $88.4 \% \pm 5.6 \%$. Both germination rates are high, which shows that the releases before and after modification, had a relatively moderate phytotoxicity on the germination of lettuce seeds. Nevertheless, we observed a significant increase in germination after the WWTP modification, which may be attributed to the reduction of major pollutants in the DW. Several studies have shown that, with the concentrations found in DW, aluminium and fluoride taken separately in synthetic solutions have a low impact on lettuce germination $[8,16,17]$. However, Charles et al. [8] showed that when these two substances are present concurrently synergistic effects may cause greater toxicity. The concentration decrease of fluoride (59\%) and aluminium (42\%) achieved by optimization of the WWTP, could explain the increase of germination rate $(+14 \%)$. This indicates the existence of a link between chemical abatement and environmental gain.

\section{Technical-economic impact}

Table 4 reports an economic breakdown of the work and equipment installed in the WWTP. The total cost was $€ 50,440$ (investment part). To these investment costs, we must also add the hiring of a chemist by

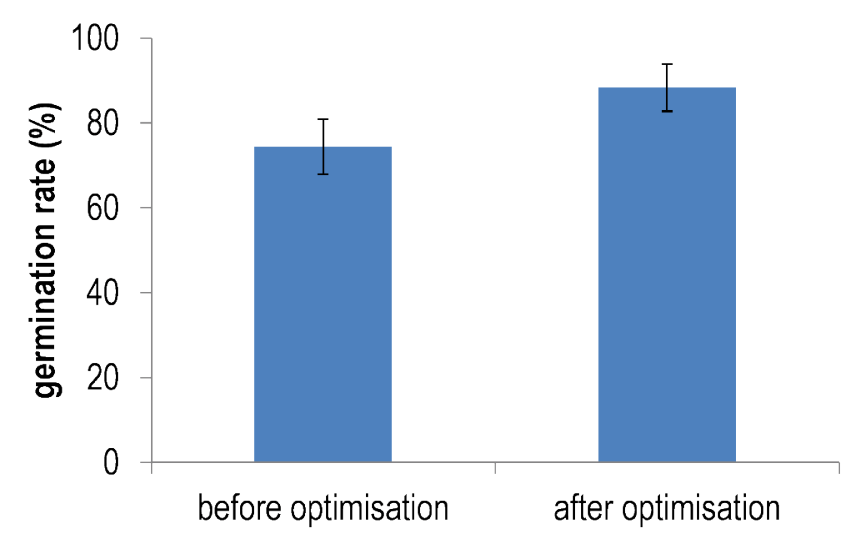

Figure 4: Impact of the WWTP modification on Lactuca sativa seed germination.

\begin{tabular}{|l|c|}
\hline materials / subcontracted work & costs in euros \\
\hline investment & 1500 \\
\hline stirrer & 5210 \\
\hline tubing - pump & 1327 \\
\hline support for neutralization tank & 3339 \\
\hline support for flocculation tank & 5250 \\
\hline connection gateway access & 4000 \\
\hline measuring equipment & 29814 \\
\hline subcontracted work & 39000 \\
\hline labor costs & $\mathbf{8 9 4 4 0}$ \\
\hline total & \\
\hline
\end{tabular}

Table 4: Financial costs of works carried out in the WWTP. 
Citation: EUVRARD E, MORIN-CRINI N, CORNU J, HUTINET J, GAVOILLE S, et al. (2015) Modification of a Wastewater Decontamination Station: Chemical, Ecotoxicological, and Technical-Economic Impacts. J Environ Anal Chem 2: 129. doi:10.41722380-2391.1000129

\begin{tabular}{|l|c|c|c|c|}
\hline Reagents & \multicolumn{2}{|c|}{ Before Optimisation } & \multicolumn{2}{c|}{ After Optimisation } \\
\hline & annual use in kg & costs in euros & annual use in kg & costs in euros \\
\hline lime & 54000 & 20007 & 47250 & 17010 \\
\hline hydrochloric acid & 60041 & 8753 & 54956 & 7694 \\
\hline sodium bisulphite & 12672 & 3077 & 9412 & 2328 \\
\hline calcium chloride & 8004 & 1964 & 0 & 0 \\
\hline flocculant & 100 & 850 & 175 & 1488 \\
\hline Total & & $\mathbf{3 4 6 5 1}$ & & $\mathbf{2 8 5 2 0}$ \\
\hline
\end{tabular}

Table 5: Comparison of amount of chemicals used and financial costs before and after modification of the WWTP.

the industrial for a year to realize the feasibility study and the transfer of the modifications on-site (cost $€ 39,000$ ). For a total cost of $€ 89,440$, the project firstly halved the pollution present in the DW, and especially the levels of aluminium, chromium and fluoride, without affecting the volume of sludge (no additional cost), and secondly reduced the DW toxicity. Moreover, changing the diagram of the WWTP and optimizing the different steps led to a gain in the reagents used for a similar industrial activity (Table 5). This unexpected result confirms the value of the project approach.

\section{Conclusions}

This study demonstrated that optimization of the WWTP was an interesting step to significantly reduce pollutant outflow in discharge waters from powder coating aluminium industry and their toxicity, this was achieved for a relatively low cost. The chemical efficiency benefits in fact led to an environmental gain. Other industrial particular processes such as mining, metallurgy, watch and jewellery industries could benefit from these results. The next goal of our project is firstly to find economically viable solutions of abatement for the organic load (reduction in COD) by the introduction of specific pre-treatments (deoiling), and secondly to continue to reduce the fluoride flux for example by using chelating resins. In this latter case, it would be essential that the water reaching the resins have the lowest load possible to avoid problems of rapid saturation, and therefore serious economic repercussions.

\section{Acknowledgments}

The authors thank the Agence de l'Eau Rhône Méditerranée Corse, the FEDER (Fonds Européens de Développement Régional) and the Conseil Régional de Franche-Comté for financial support.

\section{Reference}

1. WFD (2000) Directive 2000/60/CE of the European Parliament and of the Council establishing a framework for the Community action in the field of water policy.

2. Fuerhacker $M(2008)$ The water framework directive-can we reach the target? Water Sci Technol 57: 9-17.

3. Fuerhacker M (2009) EU water framework directive and Stockholm conventioncan we reach the targets for priority substances and persistent organic pollutants? Environ. Sci. Pollut. Res 16: 92-97.

4. Blais J.F, Dufresne S, Mercier G (1999) State of the art of technologies for metal removal from industrial effluents. J Water Sci 12: 687-711.

5. Crini G, Badot PM (2007) Traitement et épuration des eaux industrielles polluées: (in French) Presses Universitaires de Franche-Comté (Editeur), Besançon, France.

6. Barakat MA (2011) New trends in removing heavy metals from industrial wastewater. Arabian J Chem 4: 361-377.

7. Fu F, Wang QJ (2011) Removal of heavy metal ions from wastewaters: a review. J Environ Manage 92: 407-418.

8. Charles J, Sancey B, Morin-Crini N, Badot PM, Degiorgi F et al. (2011) Evaluation of the phytotoxicity of polycontaminated industrial effluents using the lettuce plant (Lactuca sativa) as a bioindicator. Ecotox Environ Safe 74 2057-2064.

9. Sancey B, Crini G (2012) Décontamination des effluents de traitement de surface par oxydation/bioadsorption sur cyclodextrine (in French). Techniques de l'ingénieur 154: 1-12.

10. Morin-Crini N, Druart C, Gavoille S, Lagarrigue S, Crini G (2013) Analytical monitoring of the chemicals present in the discharge water generated by the surface treatment industry. J Environ Protection 4: 53-60.

11. Liu DHF, Liptak BG (2000) Wastewater treatment. CRC Press (Editor), Boca Raton, FL, USA.

12. Trunfio G, Crini G (2010) The dechromatation step in wastewater treatment plants: fundamental role and optimization. Ind Eng Chem Res 49: 12217 12223.

13. Camargo JA (2003) Fluoride toxicity to aquatic organisms: a review. Chemosphere 50: 253-264.

14. Khangarot BS, Ray PK (1989) Investigation of correlation between physicochemical properties of metals and their toxicity to the water flea Daphnia magna Straus. Ecotox Environ Safe 18: 109-120.

15. Tomasik P, Magadza CHD, Mhizha S, Chirume A (1994) The metal-meta interaction in biological systems. Part III. Daphnia magna. Water Air Soil Poll 82: 695-711.

16. Jha SK, Nayak AK, Sharma K (2009) Fluoride toxicity effects in onion (Allium cepa L.) grown in contaminated soils. Chemosphere 76: 353-356.

17. Poschenrieder C, Unse B, Corrales I, Barcelo J (2008) A glance into aluminium toxicity and resistance in plants. Sci Total Environ 400: 356-368. 